\title{
Utilization of Intravenously Administered Glucose- Oligosaccharides in Growing Miniature Pigs
}

\author{
DEAN W. ANDERSEN, L. J. FILER, JR., M. Y.-C. WU-RIDEOUT, L. B. WHITE ${ }^{(33)}$, AND \\ L. D. STEGINK ${ }^{(34)}$ \\ Departments of Pediatrics and Biochemistry, The University of Iowa College of Medicine, Iowa City, Iowa, USA
}

\begin{abstract}
Summary
The ability of intravenously administered glucose or glucose oligosaccharides to supply $12 \%$ of the energy requirement of the growing miniature pig was determined. All pigs were fed a stock diet from days 5-28 of life, and a central venous catheter was inserted at 28 days. For the next 30 days, all pigs were fed both enterally and parenterally. Positive control pigs were fed the stock diet with infusions of an isotonic balanced electrolyte solution. Negative control and test animals were fed a diet containing cellulose to replace $12 \%$ of energy. Negative control animals received the balanced electrolyte solution intravenously, while test animals received either intravenous glucose or glucose oligosaccharides at levels providing $12 \%$ of energy. Carbohydrate utilization was measured by urinary loss of carbohydrate, as well as by growth and body composition. Chemical analyses of the urine indicated utilization of both glucose and glucose oligosaccharides. Glucose oligosaccharides were utilized less well $(85 \%)$ than glucose $(\geq 99 \%)$. No statistically significant differences in weight gain were noted between groups, although weight gain in negative control animals and those animals infused with glucose oligosaccharide solutions were lower than those in the other groups. Body fat analyses also indicate that glucose oligosaccharide solutions were less effective than glucose as an energy source.
\end{abstract}

\section{Speculation}

Infusion of solutions containing oligosaccharides composed of repeating glucose units linked by $\alpha$-1,4-glucosidic bonds can supply considerably more energy per osmole infused than glucose. If the human infant utilizes intravenously administered oligosaccharides as well as the growing pig, oligosaccharides may be able to partially replace glucose in parenteral feeding regimens.

The quantity of carbohydrate-derived energy that can be administered by peripheral vein is limited by osmolarity, and the ability of man to handle infused water. The quantity of energy delivered per osmole infused could be increased if oligosaccharides composed of repeating glucose units linked by $\alpha$-1,4-glucosidic bonds could be utilized. Recently, solutions have been formulated from hydrolyzed starch that contain mixtures of oligosaccharides, and preliminary studies have been carried out in adult humans $(2,5,6,7,8,12,30,31)$. A critical question is whether intravenously administered glucose-oligosaccharides can be utilized efficiently by the growing organism.

Inasmuch as relatively poor utilization of glucose oligosaccharides was noted at high infusion rates in both adult human and animal studies, it is unlikely that glucose oligosaccharides will serve as the sole carbohydrate energy source for parenteral nutrition regimens. Intravenous solutions of glucose oligosaccharides would have greatest use as a supplemental carbohydrate energy source in patients receiving other nutrients orally.

The present study compares the ability of intravenously administered glucose or a glucose-oligosaccharide solution to supply
$12 \%$ of the total energy requirement of the growing miniature pig. The ability of glucose and oligosaccharide solutions to meet energy requirements was determined by measuring loss of infused carbohydrate in the urine, and by evaluation of animal growth and body composition.

\section{MATERIALS AND METHODS}

Pitman-Moore strain miniature pigs were used in these experiments. Four groups of animals were studied, using two different diets. Diet composition is shown in Table 1. Diet I is the positive control diet. It contained $21 \%$ protein, $65 \%$ carbohydrate, $10 \%$ lipid, $0.65 \%$ cellulose, $3.35 \%$ vitamin-mineral mix, and provided 434 kcalories of energy/ $100 \mathrm{~g}$ feed. Diet II, was formulated so that cellulose replaced $12 \%$ of the energy in Diet I. It contained $21 \%$ protein, $52 \%$ carbohydrate, $10 \%$ lipid, $13.65 \%$ cellulose, $3.35 \%$ vitamin-mineral mix, and provided $382 \mathrm{kcalories}$ of energy/100 $\mathrm{g}$ feed. To feed, both diets were mixed with water to yield a formula containing $25 \%$ total solids.

The study outline is shown in Figure 1. Neonatal pigs were suckled on the sow from birth until 5 days of age. At 5 days of age the animals were taught to nipple feed, and were fed Diet I until 28 days of age. At 28 days all pigs in a litter with birth weights between $800-1200 \mathrm{~g}$ that had gained 12 or more $\mathrm{g} / 100 \mathrm{kcalories}$ of energy consumed were selected to continue the study. Within each litter, one pig was randomly assigned to each of the 4 treatment groups. A total of 5 animals were studied in each group. Each pig was anesthetized, a central catheter surgically implanted (11), and the animal fed according to its assigned group. From 28 through 58 days of life, all animals were fed enterally and parenterally. Antibiotics were administered as described in our earlier intravenous studies (1). Animals were weighed daily; body length and girth were determined weekly (1).

Positive control animals were fed Diet I ad libitum with daily infusions through the catheter with a balanced electrolyte solution (Normosol-R (32), Abbott Laboratories, North Chicago, IL; 1.5$2.5 \mathrm{ml} / \mathrm{kg} / \mathrm{h}$ ) for the 30 -day intravenous feeding period. Food consumption was determined as described previously (1). Negative control animals were pair-fed to the positive control animals with an equivalent weight of Diet II, and were infused with Normosol$\mathrm{R}(1.5-2.5 \mathrm{ml} / \mathrm{kg} / \mathrm{h})$ through the catheter for the 30-day intravenous feeding period. These animals received $12 \%$ less energy than the positive control animals.

Test animals, pair-fed to positive control animals with an equivalent weight of Diet II, received either a $10 \%$ glucose or glucoseoligosaccharide solution (Formula X2916, Abbott Laboratories, North Chicago, IL) intravenously in a quantity sufficient to supply the $12 \%$ energy deficiency of Diet II. Oligosaccharide distribution in the solution used is shown in Table 2. The absence of maltose and glucose in the mixture was confirmed by enzymatic assay for glucose (1) and by thin layer chromatography (Silica gel GF; butanol:ethanol:water; $85: 45: 50$; ceric molybdate spray used for detection).

The oligosaccharide solution was supplied by the manufacturer 
Table 1. Diet compositions

\begin{tabular}{lcc}
\hline \multicolumn{1}{c}{ Component $^{\prime}$} & $\begin{array}{c}\text { Diet I } \\
\text { \% by Weight }\end{array}$ & $\begin{array}{c}\text { Diet II } \\
\text { \% by Weight }\end{array}$ \\
\hline Dry skim milk' $^{2}$ & 50.0 & 50.0 \\
Amigen $^{2}$ & 4.0 & 4.0 \\
Dextrose $_{\text {Corn starch }}{ }^{3}$ & 10.0 & 6.0 \\
Corn syrup solids $^{4}$ & 10.0 & 6.0 \\
Corn oil $^{5}$ & 12.5 & 7.5 \\
CaHPO $_{4} \cdot 2 \mathrm{H}_{2} \mathrm{O}$ & 9.5 & 9.5 \\
$\mathrm{NaCl}_{\text {MgSO }}$ & 1.7 & 1.7 \\
${\text { Vitamin } \text { mix }^{7}}_{\text {Mineral mix }^{6}}$ & 0.5 & 0.5 \\
Cellulose $^{8}$ & 0.15 & 0.15 \\
\hline
\end{tabular}

'J. M. Swank Instant (spray) non-fat milk solids. Plainview Milk Association, Plainview, MN Lot \#55964.

${ }^{2}$ Casein hydrolysate. Mead Johnson, Evansville, IN.

${ }^{3}$ Corn starch, National Starch \& Chemical Corp., Indianapolis, IN.

${ }^{4}$ Corn Syrup Solids, Clinton Corn Processors, Clinton, IA.

${ }^{5}$ Corn Oil (Mazola), CPC International, Inc., Englewood Cliffs, NJ.

${ }^{6}$ Mineral mixture supplied in $\mathrm{g} / 100 \mathrm{~g}$ diet: $\mathrm{Ca}, 0.37, \mathrm{P}, 0.28 ; \mathrm{Mg}, 0.03$, $\mathrm{Zn}, 0.005 ; \mathrm{Mn}, 0.002 ; \mathrm{Cu}, 0.00 \mathrm{I} ; \mathrm{Fe}, 0.008 ; \mathrm{I}, 0.003 ; \mathrm{Na}, 0.19 ;$ and $\mathrm{Cl}, 0.28$.

${ }^{7}$ Vitamin mixture supplied in $100 \mathrm{~g}$ of diet: choline, $71 \mathrm{mg}$; thiamin, $0.17 \mathrm{mg}$; riboflavin, $0.24 \mathrm{mg}$; nicotinic acid, $2.1 \mathrm{mg}$; pantothenic acid, 2.38 $\mathrm{mg}$; pyridoxin, $0.24 \mathrm{mg}$; folic acid, $0.10 \mathrm{mg}$; B12, $2.10 \mu \mathrm{g}$; Vitamin A, 210 I.U.; Vitamin D, 21 I.U.; Vitamin E, 0.05 I.U.

${ }^{8}$ Cellulose non-nutritive fiber, Catalog 16-0390, Lot 42207, General Biochemical Corp., Chargrin Falls, $\mathrm{OH}$.

STUDY OUTLINE

\begin{tabular}{|c|c|c|}
\hline BIRTH & 5 DAYS & 58 DAYS \\
\hline -SOW FED $\rightarrow$ & - COMPLETE DIET $\longrightarrow$ & $\left|\begin{array}{l}- \text { COMPLETE DIET + IV NORMOSOL-R } \longrightarrow \\
- \text { DEFICIENT DIET + IV MORMOSOL-R } \longrightarrow \\
- \text { DEFICIENT DIET + IV GLUCOSE- } \longrightarrow \\
- \text { DEFICIENT DIET + IV OLIGOSACCHARIDES } \rightarrow\end{array}\right|$ \\
\hline
\end{tabular}

Fig. 1. Utilization of intravenously administered oligosaccharides by growing miniature pigs.

as a $25 \%$ solution $(\mathrm{w} / \mathrm{v})$. This was diluted under a laminar flow hood by adding $400 \mathrm{ml}$ of the $25 \%$ oligosaccharide solution to 600 $\mathrm{ml}$ of Normosol-R (Abbott Laboratories, North Chicago, IL) in empty evacuated sterile bottles.

The amount of energy to be infused into each test animal was calculated from the total energy intake of the positive control pair-fed pig 2 days before the current date. This value $(\mathrm{kcal} / \mathrm{kg})$ was reduced by $12 \%$ and multiplied by the body weight of the test animal on that same day. Intravenous solutions were administered by infusion pump (Life Care, Abbott Laboratories, North Chicago, IL) at a constant rate $24 \mathrm{~h}$ a day, with the exception of that time needed to weigh the animals and change infusion sets. The actual amount of intravenous solution administered was calculated by difference in bottle weight.

Blood samples $(8-10 \mathrm{ml}$ ) were taken (superior vena cava) before surgery (27 days) and at weekly intervals thereafter at 0800 hours. Blood samples were analyzed for serum amylase, albumin, total protein, inorganic phosphorus, cholesterol, urea nitrogen, uric acid, alkaline phosphatase, LDH, bilirubin, and glutamate-oxaloacetate transaminase on automated analyzers (SMA 12/60) by the Pathology Department of the University of Iowa Hospitals and Clinics. Terminal blood samples were analyzed for all of the above biochemical indices plus plasma sodium, potassium, chloride, $\mathrm{CO}_{2}$, creatinine, and free amino acids. Plasma samples for amino acid analyses were prepared and analyzed as described by Stegink et al. (26). Free and total plasma glucose were determined at weekly intervals during the infusion period by the methods described in our previous study (1).

Upon completion of the study, each animal was fasted overnight and given a lethal dose of sodium pentobarbital. An autopsy was performed, and major organs weighed. The carcass and liver were frozen and ground for analysis of fat, water, ash, and nitrogen as previously described (10).

Twenty-four h urine samples were collected before implantation of the catheter and at weekly intervals during the intravenous infusion period for determination of glucose, maltose, and total glucose excretion. Urinary glucose and total glucose excretion were measured as described previously (1). Urine samples were also treated with $\alpha$-glucosidase (maltase) as described earlier (1). Maltose and maltotriose, but not maltotetraose $(17,23)$ are substrates for this enzyme. Thus, this method measures maltose plus maltotriose excretion.

The oligosaccharide distribution of urinary carbohydrate in the urine of oligosaccharide-infused animals was determined by gel permeation chromatography using BioGel P-2 resin (BioRad, Richmond, CA) as described by John et al. (18). This allowed calculation of the amount of maltose and maltotriose excreted.

Statistical analyses used the independent $t$ test (25) and analysis of variance with randomized complete block design (21) to test for differences between groups.

\section{RESULTS}

Plasma free and total glucose values during the intravenous infusion period are shown in Table 3. Free glucose levels and total glucose values were significantly lower $(P \leq 0.05)$ in animals infused with glucose oligosaccharides than in the other groups. However, no significant differences were noted between free and total glucose values in test animals infused with oligosaccharides, indicating no accumulation of oligosaccharides in the blood.

Urinary carbohydrate excretion during the 30-day infusion period is shown in Table 4. Positive control animals, fed ad libitum and infused with Normosol-R, excreted an average of $0.19 \mathrm{~g}$ glucose/day during the 30-day infusion period. No maltose or

Table 2. Distribution of glucose oligosaccharides ${ }^{1}$

\begin{tabular}{cc}
\hline Chain length & $\%$ \\
\hline 1 & 0 \\
2 & 0 \\
3 & 24.8 \\
4 & 14.9 \\
5 & 19.2 \\
6 & 30.9 \\
7 & 4.8 \\
8 & 2.3 \\
9 & 1.2 \\
$>10$ & 1.9 \\
\hline
\end{tabular}

${ }^{1}$ Manufacturers analysis of X2916, Lot $83-496-\mathrm{DH}$ as determined by gel permeation chromatography using BioGel $\mathrm{P}-2$ resin in the procedure described by John et al. (18).

Table 3. Plasma free and total glucose levels during infusion

\begin{tabular}{lcc}
\hline \multicolumn{1}{c}{ Animal Group } & $\begin{array}{c}\text { Free glucose } \\
(\mathrm{mg} / \mathrm{dl})\end{array}$ & $\begin{array}{c}\text { Total glucose } \\
(\mathrm{mg} / \mathrm{dl})\end{array}$ \\
\hline${\text { Complete } \mathrm{diet}^{2}+\text { IV Normosol-R }}^{3}$ & $141 \pm 25^{1}$ & $145 \pm 30^{1}$ \\
Deficient diet $^{3}$ + IV Normosol-R & $140 \pm 26$ & $136 \pm 28$ \\
$\begin{array}{l}\text { Deficient diet } \\
\text { Deficient } \text { diet }^{3} \text { + IV Glucose }\end{array}$ & $141 \pm 26$ & $137 \pm 24$ \\
rides & $113 \pm 20^{4}$ & $117 \pm 21^{4}$ \\
\end{tabular}

\footnotetext{
${ }^{1}$ Data shown are mean \pm S.D. of all plasma samples taken during the intravenous infusion period. ( $n=20$ per group).

${ }^{2}$ Diet I.

${ }^{3}$ Diet II.

${ }^{4}$ Differ significantly $(P=0.05)$ from values in other groups.
} 
Table 4. Carbohydrate excretion

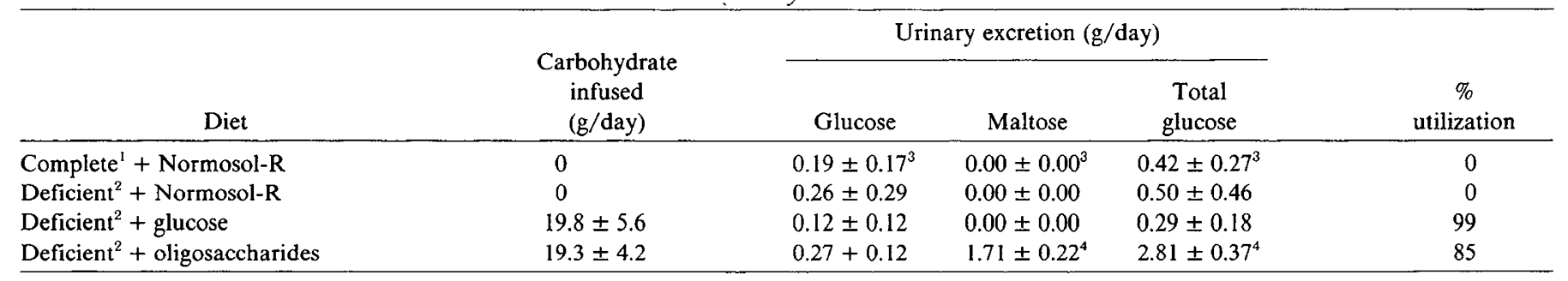

' Diet I, 5 animals/group.

${ }^{2}$ Diet II, 5 animals/group.

${ }^{3}$ Data expressed as mean \pm S.D., $n=20$.

${ }^{4}$ Differ significantly, $P \leq 0.001$ from values on all other diets.

Table 5. Energy intake during infusion

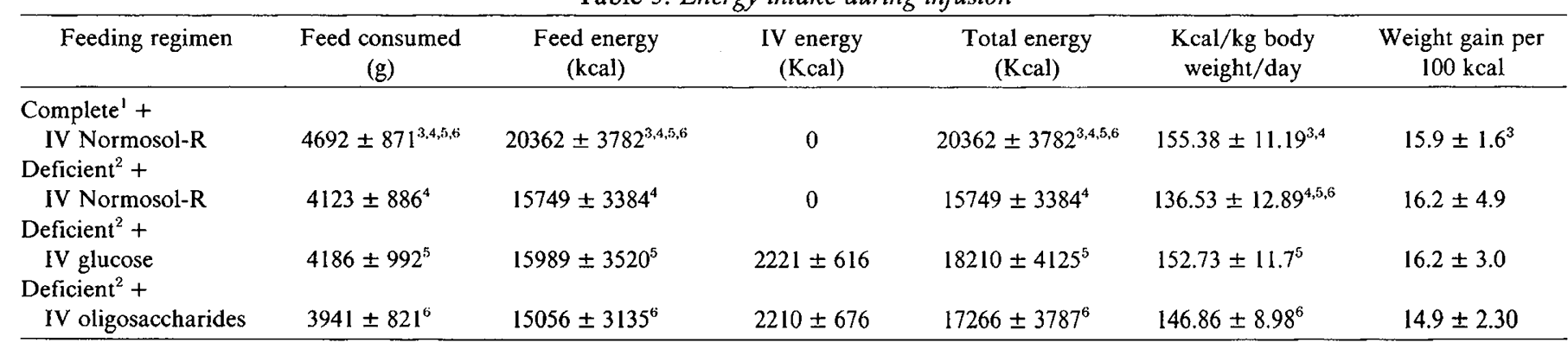

' Diet $\mathrm{I}$.

${ }^{2}$ Diet II.

${ }^{3}$ Data expressed as mean \pm S.D.

${ }^{4,5,6}$ Values in the same column having similar superscripts differ significantly $(P=0.05)$.

maltotriose were detected using the $\alpha$-glucosidase (maltase) assay. Total urinary glucose averaged $0.42 \mathrm{~g} /$ day. Similar values were noted in negative control animals infused with Normosol- $R$ and test animals infused with glucose. Free glucose excretion averaged 0.26 and $0.12 \mathrm{~g} /$ day respectively in these two groups, whereas total glucose averaged 0.5 and $0.29 \mathrm{~g} /$ day respectively. Free glucose excretion in animals infused with oligosaccharides was similar to values noted in positive control animals, averaging 0.27 $\mathrm{g} /$ day. However, maltose plus maltotriose excretion as determined by $\alpha$-glucosidase assay was significantly elevated $(P=0.001)$, averaging $1.91 \pm 0.37 \mathrm{~g} /$ day. Total glucose excretion (glucose + maltose + maltotriose + glucose oligosaccharides) was significantly higher $(P \leq 0.001)$ in animals infused with the oligosaccharide solution, averaging $2.81 \pm 0.37 \mathrm{~g} /$ day. Gel permeation chromatography of urine from oligosaccharide-infused animals gave similar results. Excretion of maltose, maltotriose, and oligosaccharides equal to or greater in size than maltotetraose was $1.71 \pm$ $0.22,0.38 \pm 0.19$, and $0.46 \pm 0.20 \mathrm{~g} /$ day respectively. Thus, of the total carbohydrate excreted, $9.6 \%$ was excreted as glucose, $60.7 \%$ as maltose, $16.3 \%$ as maltotriose and $13.5 \%$ as oligosaccharides equal to or greater in size than maltotetraose.

The utilization rate of oligosaccharides, calculated from chemical analysis of the urine ranged from $84 \%$ during the first wk of infusion to $87 \%$ during the last wk of the infusion, with a mean utilization value of $85 \%$.

Mean ( \pm S.D.) body weight of positive control animals upon completion of the intravenous portion of the study was $6111 \pm$ $1057 \mathrm{~g}$. These pigs were slightly larger than negative control animals $(5274 \pm 1363 \mathrm{~g})$ or test animals infused with glucose $(5683$ $\pm 1392 \mathrm{~g})$ or oligosaccharides (4314 $\pm 1148 \mathrm{~g})$. Although body weights followed the anticipated direction, in that negative control pigs were smaller than positive control pigs or animals infused with glucose or oligosaccharides, these differences are not significant at the 0.05 level when the data were evaluated using analysis of variance with randomized complete block design.

Mean ( \pm S.D.) weight gain of animals fed intravenously with glucose (3043 $\pm 1266 \mathrm{~g})$ approximated that of the positive control group $(3272 \pm 909 \mathrm{~g})$. The weight gain of negative control animals was $2666 \pm 1303 \mathrm{~g}$ and was similar to that of treated animals infused with oligosaccharides $(2612 \pm 869 \mathrm{~g})$. Analysis of variance indicated no significant differences in weight gain.

Food intake in animals fed the energy deficient diet was lower $(P \leq 0.05)$ than in positive control pigs (Table 5) for two reasons. First, when food waste exceeded $50 \mathrm{~g}$, we were unable to add that additional amount to the day's feeding without overfeeding the animals. Over the course of the 30-day study, this amounted to $6.5 \%$ less food or $305 \mathrm{~g}$ feed. Second, pair-fed animals received less food because of the 2 day delay necessary for food waste calculations. All animals had self-selected low food intakes on day 28 , (about $20 \mathrm{~g}$ or less on the day of surgery). Thus, pair-fed animals received a lower food intake on day 28 (self-selected due to surgery) and on day 30 (as a result of pair-feeding to the intake of positive control animals on day 28). This fact decreased normal food intake by about $82 \mathrm{~g} /$ day. Thus, the low intake on these two days decreased food intake by $164 \mathrm{~g}$. These two factors account for the $469 \mathrm{~g}$ of the decreased feed intake of pigs fed the energy deficient diet.

Animals infused with oligosaccharide solutions received slightly less total energy than animals infused with glucose. However, when these data are expressed as energy $/ \mathrm{kg}$ body weight/day, no significant differences were noted between positive control animals and animals infused with glucose or oligosaccharide solutions. By contrast, animals fed the energy deficient diet and infused with Normosol had a significantly lower energy intake. Values in these animals were $12 \%$ less than values in positive control animals. Feed efficiency, expressed as weight gain/100 kcal energy did not differ significantly between groups, indicative of similar energy utilization.

Mean values for carcass composition, length and girth are shown in Table 6. Analysis of variance showed no significant difference in length and girth between treatment groups. Carcass fat in positive control animals $(7.76 \%)$ was comparable to that noted in treated animals receiving intravenous glucose $(7.24 \%)$. However, positive control animals were significantly $(P \leq 0.05)$ fatter than negative control animals (5.18\%). The carcass fat content of animals infused with oligosaccharide solutions was also 
Table 6. Body length, girth and carcass composition at end of infusion

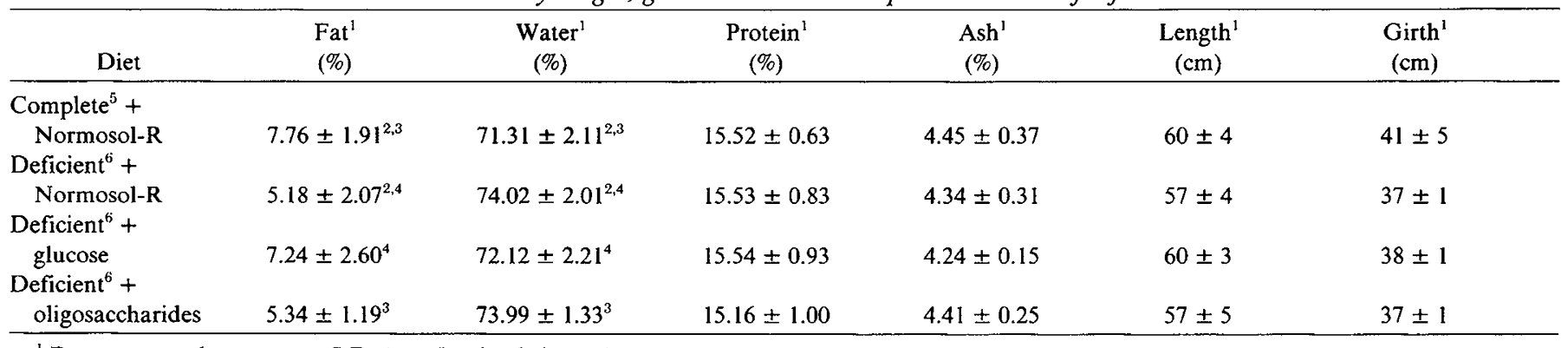

${ }^{1}$ Data expressed as mean \pm S.D. ( $n=5$ animals/group).

${ }^{2,3,4}$ Values in the same column having similar superscripts differ significantly $(P \leq 0.05)$.

"Diet I.

${ }^{4}$ Diet II.

significantly lower than that of the positive control animals. Since carcass water content is inversely proportional to carcass fat content, positive control animals and animals receiving intravenous glucose had significantly less body water than negative control pigs or pigs receiving oligosaccharides intravenously. The $\%$ of ash and protein in carcass did not differ significantly by treatment group. No differences in liver composition were noted among groups. No statistically significant differences in organ weights at autopsy were noted among groups.

Blood samples obtained at weekly intervals and upon completion of the study were analyzed for SMA $12 / 60$ profiles. No significant changes were observed in any of these indices with age or treatment.

\section{DISCUSSION}

Urinary carbohydrate excretion data indicate utilization of intravenous glucose oligosaccharides solutions by the growing miniature pig, but at a lower rate than glucose. Animals infused with the oligosaccharides excreted $14-17 \%$ of infused glucose oligosaccharide in the urine. By contrast, animals infused with glucose lost less than $1 \%$ of infused glucose in urine.

The urinary excretion data are consistent with body composition data. Although no significant differences in final body weight were noted among groups, carcass fat composition did vary (Table 6). Body fat content can be used as an indicator of the energy content of diets provided the growing organism. For example, human infants fed an energy deficient diet continue to grow, but have less body fat (14). The carcass fat data in these pigs indicate that animals fed the energy deficient diet supplemented with intravenous glucose maintain body fat stores as well as the animals fed the energy complete diet. By contrast, animals fed the energy deficient diet supplemented with a balanced electrolyte solution had a significantly lower carcass fat content (5.18\%). Animals fed the energy deficient diet supplemented with intravenous oligosaccharides had a carcass fat content of $5.34 \%$, greater than that of animals fed the energy deficient diet supplemented with Normosol-R, but significantly less $(P \leq 0.05)$ than that found in animals infused with glucose (7.24\%).

The differences in carcass fat content between animals infused with glucose and those receiving oligosaccharide infusions are consistent with the difference in energy intake between groups and the urinary loss of oligosaccharides. Animals infused with oligosaccharides received slightly less total energy than animals infused with glucose $(\Delta=944 \mathrm{kcal})$. This difference in available energy increases when the intravenous energy intake of oligosaccharide-infused animals is corrected for the $15 \%$ of infused oligosaccharide energy excreted in the urine $(332 \mathrm{kcal})$. Thus, animals infused with glucose received $1276 \mathrm{kcal}$ more total energy than animals infused with the oligosaccharide solution. This difference in energy intake can account for the observed difference in carcass fat. The carcass fat content of glucose-infused animals was $298 \mathrm{~g}$ $(4.113 \mathrm{~kg} \times 7.24 \% \mathrm{fat})$, whereas that of oligosaccharide-infused animals was $202 \mathrm{~g}(3.781 \mathrm{~kg} \times 5.34 \% \mathrm{fat})$, a difference of $96 \mathrm{~g}$.
Thorbek (27) has reviewed the available data on energy requirements for fat and protein biosynthesis in the growing pig. These data indicate $13.0 \pm 0.62 \mathrm{kcal}$ (mean \pm S.D.) are required for synthesis of $1 \mathrm{~g}$ fat, whereas $11.1 \pm 2.60 \mathrm{kcal}$ are required for synthesis of $1 \mathrm{~g}$ protein. Thus, $1248 \mathrm{kcal}$ would be required to synthesize the additional $96 \mathrm{~g}$ fat lacking in oligosaccharide-infused animals compared to glucose-infused animals. These data indicate that energy intake differences account for the lower carcass fat content of oligosaccharide-infused animals.

Energy intake differences can also account for much of the difference in carcass weight noted between glucose- and oligosaccharide-infused animals. It has been shown that the water content of adipose tissue of the infant is higher than that of the adult (4). On the basis of these data we suggest that the water content of adipose tissue of the 1-2-month-old pig is about $30 \%$. Therefore, the deposition of $96 \mathrm{~g}$ fat will be equivalent to $137 \mathrm{~g}$ adipose tissue. Assuming that body fat synthesis accounts for $1248 \mathrm{kcal}$ of the $1276 \mathrm{kcal}$ difference in calculated energy intake between glucoseand oligosaccharide-infused animals, and that the remaining 28 kcal were used for synthesis of lean body mass, $2.52 \mathrm{~g}$ protein would be synthesized if $11.1 \mathrm{kcal}$ energy are required to deposit 1 $\mathrm{g}$ protein. Because the protein content of lean body mass approximates $20 \%$, the synthesis of $2.52 \mathrm{~g}$ protein would result in the formation of $12.6 \mathrm{~g}$ lean body mass. Thus, the difference in energy intake would result in the gain of $137 \mathrm{~g}$ adipose tissue and $13 \mathrm{~g}$ lean body mass. This would account for $150 \mathrm{~g}$ of the observed difference in carcass weight $(332 \mathrm{~g})$.

Similar calculations can be made for negative control animals fed the energy deficient diet supplemented with intravenous Normosol. These animals received $2461 \mathrm{kcal}$ less energy than glucoseinfused animals. Total carcass fat in negative control animals was $188 \mathrm{~g}, 110 \mathrm{~g}$ less than carcass fat values in glucose-infused animals. The synthesis of this fat requires $1430 \mathrm{kcal}$, leaving $1031 \mathrm{kcal}$ available for synthesis of lean body mass. This $1031 \mathrm{kcal}$ energy would synthesize $92.9 \mathrm{~g}$ protein, or $464 \mathrm{~g}$ lean body mass. The expected increase in adipose tissue $(157 \mathrm{~g})$ plus increased lean body mass ( $464 \mathrm{~g}$ ) totals $621 \mathrm{~g}$, approximating the observed difference in carcass weight $(472 \mathrm{~g})$ between groups.

Glucose oligosaccharide utilization in the growing pig (85\%) was better than that observed in fasted normal human volunteers infused at similar levels. The mean oligosaccharide infusion rate in pigs was $0.18 \mathrm{~g} / \mathrm{kg} / \mathrm{h}$ during the 30 -day infusion period. Bibby et al. (6) reported urinary losses of $15-45 \%$ of infused oligosaccharides in fasted normal volunteers receiving Caloreen at $0.25-0.5$ $\mathrm{g} / \mathrm{kg} / \mathrm{h}$. Finke and Reinauer (12) reported urinary losses of 24$39 \%$ of infused oligosaccharides in normal volunteers receiving $0.25-0.50 \mathrm{~g} / \mathrm{kg} / \mathrm{h}$ of an undescribed oligosaccharide mixture (310 glucose units).

Differences in the oligosaccharide composition of various preparations must be considered when comparing utilization. Most oligosaccharide infusion studies carried out in Europe $(2,5,6,7$, 8) used Caloreen (Milner Scientific and Medical Research Co., Ltd., Liverpool, England), a mixture of glucose oligosaccharides with an average size of 5 glucose units. Approximately $75 \%$ of the 
glucose residues in this preparation are linked by $\alpha$-1,4-glucosidic bonds, with $25 \%$ containing the $\alpha$-1,6-glucosidic linkage (20). Although the Caloreen studies indicate oligosaccharide utilization, the extent of utilization was thought limited by the presence of oligosaccharides containing $\alpha$-1,6-glucosidic bonds, because such bonds are resistant to hydrolysis by $\alpha$-amylase.

The oligosaccharide mixture used in our study contained virtually all of the glucose units linked by $\alpha-1,4$-glucosidic bonds, thus utilization should not be limited by an ability of $\alpha$-amylase to hydrolyze $\alpha$-1,6-glucosidic bonds. When Young et al. $(30,31)$ infused a similar oligosaccharide preparation into fasting normal adult human volunteers at $0.11,0.15$, and $0.3 \mathrm{~g} / \mathrm{kg} / \mathrm{h}$, they reported urinary losses of $21 \%, 43 \%$, and $62 \%$ respectively. Although better utilization of this product by the growing pig may reflect a species difference, it may also reflect a difference due to growth, or a better utilization of oligosaccharides when other nutrients are supplied. If the better utilization of glucose oligosaccharides by the pig represents a nutrient response, this effect probably does not involve insulin. Young et al. (31) recently reported that simultaneous infusion of insulin and glucose oligosaccharides did not improve oligosaccharide utilization in adult humans. This contrasts to results obtained with intravenous maltose (29) where insulin had a significant effect upon utilization.

The kinds of oligosaccharide-derived compounds excreted by the pig during oligosaccharide infusion were similar to those excreted by man. The size distribution of excreted oligosaccharides suggests a sequential degradation of larger oligosaccharides to maltose and maltotriose, with utilization of maltose and maltotriose being rate limiting. In the growing pig, $9.6 \%$ of the total excreted carbohydrate was glucose, $60.7 \%$ maltose, $16.3 \%$ malto triose, and $13.5 \%$ higher oligosaccharides. Thus, maltose + maltotriose accounted for $77 \%$ of the total carbohydrate excreted by the pig. Similar data are reported in humans. Bibby et al. (6) report that the size distribution of urinary oligosaccharide excretion products decreased markedly after the time of injection, with smaller components predominating at longer time intervals. Young et al. (30) reported that the composition of excreted carbohydrate in normal volunteers infused with a similar oligosaccharide preparation was $10 \%$ glucose, $30 \%$ maltose, $20 \%$ maltotriose, and $40 \%$ as higher polymers of glucose.

The large amount of maltose excreted by oligosaccharide-infused animals is surprising. The manufacturer's analysis of the oligosaccharide mixture indicated no maltose. Because of the high urinary maltose excretion, the glucose and maltose content of the solution was checked: (1) using the enzymic assay for glucose (1); (2) by thin layer chromatography; and (3) by BioGel P-2 chromatography. These data indicate $0.1 \%$ or less maltose in the solution infused. Over the 30-day infusion period, oligosaccharide infusion averaged $19.2 \mathrm{~g} /$ day, equivalent to a maximum of $20 \mathrm{mg}$ maltose daily. However, maltose excretion averaged $1.71 \mathrm{~g} /$ day, suggesting production of maltose from higher oligosaccharides. The apparently poor utilization of maltose is puzzling. Previous studies indicate good utilization (84-89\%) of intravenously administered maltose by the growing miniature pig (1).

There are several possible explanations for the high urinary maltose excretion: (1) maltose may be poorly utilized when infused with higher oligosaccharides; (2) maltotriose (present in relatively large quantities in the mixture) may be converted to maltose during reabsorption from the glomerular filtrate; or (3) maltose may be produced as the metabolic end product from the larger glucose oligosaccharides. Further experiments will be required to distinguish between these possibilities.

The mechanism by which infused glucose-oligosaccharides are metabolized is not clear. Infused oligosaccharides may be partially hydrolyzed by plasma $\alpha$-amylase to yield glucose. Some oligosaccharides may enter cells by passive diffusion as has been reported for maltose in diaphragm (28). Once inside the cell, the oligosaccharides might be hydrolyzed by $\alpha$-amylase (EC 3.2.1.1), glucoamylase (EC 3.2.1.3), maltase (EC 3.2.1.20), or phosphorylase (EC 2.4.1.1) to yield glucose or phosphorylated hexose derivatives. It is not clear whether all tissues contain the enzymes necessary to metabolize the larger oligosaccharides. Although $\alpha$-amylase is present in intestinal mucosa and pancreas $(3,9,19)$, it is not present in human liver (15). However, glucoamylase is present in liver lysosomes (15). Alternatively, a portion of the infused oligosaccharides may be converted to higher oligomers of glucose without hydrolysis to glucose. A pathway for the synthesis of oligosaccharides from maltose has been reported in rat liver (16), and maltose, maltotriose, and maltotetraose are normally present in that tissue (13). The kidney probably plays a major role in oligosaccharide metabolism. Glucose oligosaccharides cleared to the glomerular filtrate may be hydrolyzed and reabsorbed in the renal tubule brush border by mechanisms similar to those used in the gastrointestinal tract. Previous studies in dogs (24), rabbits (22), and man (29) suggest that the kidney is a major determinant of the metabolism of infused maltose. Higher oligosaccharides may be metabolized similarly.

The data indicate reasonable utilization of glucose oligosaccharides by the healthy growing miniature pig when infused at $12 \%$ energy. Most parameters measured (other than body fat) in animals fed the deficient diet supplemented with intravenous infusions of glucose-oligosaccharides were similar to values noted in animals fed the deficient diet supplemented with intravenous glucose infusions. The data suggest a possible role for oligosaccharide infusion as a supplemental carbohydrate energy source.

\section{REFERENCES AND NOTES}

1. Andersen, D. W., Wu-Rideout, M. Y-C., Filer, L. J. Jr., and Stegink, L. D.: Utilization of intravenously administered maltose by the growing miniature pig. J. Nutr., 111: 1185 (1981).

2. Atherton, S. T. and Wright, D. M.: Initial studies into intravenous Caloreen in man. In: N. P. Mallick: Glucose Polymers in Health and Disease: The Role of Caloreen, pp. 77-86 (MTP Press Limited, Lancaster, England, 1977).

3. Auricchio, S., Rubino, A., and Mürset, G.: Intestinal glycosidase activities in the human embryo, fetus, and newborn. Pediatrics, 35: 944 (1965).

4. Baker, G. L.: Human adipose tissue composition and age. Am. J. Clin. Nutr., 22: 829 (1969).

5. Berlyne, G. M., Booth, E. M., Brewis, R. A. L., Mallick, N. P., and Simons, P. J.: A soluble glucose polymer for use in renal failure and calorie-deprivation states. Lancet, 1: 689 (1969).

6. Bibby, R. J., Davies, D., Mallick, N. P., Atherton, S. T., Wright, D. M., Ricketts, C. R., and Milner, J.: Intravenous infusion of a dextrin, Caloreen, in human subjects: Metabolic studies. Br. J. Nutr., 38: 341 (1977).

7. Bibby, R. J., Davies, D., Mallick, N. P., Atherton, S. T., Wright, D. M., Jones, E. S., Ricketts, C. R., Hall, M., and Milner, J.: Studies of the metabolism of a dextrin. Caloreen, administered intravenously in human subjects. Clin. Sci. Mol. Med., 46: 7P (1974).

8. Davies, D. and Mallick, N. P.: Metabolic studies using infusions of glucose polymers and disaccharides. In: N. P. Mallick: Glucose Polymers In Health and Disease: The Role of Caloreen, pp. 87-94 (MTP Press Limited, Lancaster, England, 1977).

9. Eggermont, E.: The hydrolysis of the naturally occurring $\alpha$-glucosides by the human intestinal mucosa. Eur. J. Biochem., 9: 483 (1969).

10. Filer, L. J., Jr., Fomon, S. J., Anderson, T. A., Andersen, D. W., Rogers, R. R., and Jensen, R. L.: Growth, serum chemical values and carcass composition of Pitman-Moore miniature pigs during the first eight weeks of life. J. Nutr., 103: 425 (1973).

11. Filer, L. J., Jr., Stegink, L. D., and Andersen, D. W.: Prevention and correction of essential fatty acid deficiency in the neonatal pig. In: A. L. Barlow: Liposyn Research Conference Proceedings, pp. 21-27 (Abbott Press, North Chicago, IL, 1979).

12. Finke, C. and Reinauer, H.: Utilization of maltose and oligosaccharides after intravenous infusion in man. Nutr. Metab., 21(Suppl. 1): 115 (1977).

13. Fishman, W. H. and Sie, H-G.: The presence of maltose, maltotriose and maltotetraose in liver. J. Am. Chem. Soc., 80: 121 (1958).

14. Fomon, S. J., Filer, L. J., Jr., Ziegler, E. E., Bergmann, K. E., and Bergmann, R. L.: Skim milk in infant feeding. Acta Paediatr. Scand., 66: 17 (1977)

15. Gamklou, R. and Schersten, T.: Activity of $\alpha$-amylase and $\alpha$-1,4-glucosidase in human liver tissue. Scand. J. Clin. Lab. Invest., 30:201 (1972)

16. Giri, K. V., Nagabhushanam, A., Nigam, V. N., and Belavadi, B.: Synthesis of oligosaccharides from maltose by rat liver. Science, 121: 898 (1955).

17. Gutman, I. Maltose.: In: H. U. Bergmeyer: Methods of Enzymic Analysis, 2nd English Edition, pp. 1185-1188 (Academic Press, New York, 1974).

18. John, M., Trenel, G., and Dellweg, H.: Quantitative chromatography of homologous glucose oligomers and other saccharides using polyacrylamide gel. J. Chromatogr., 42: 476 (1969).

19. Lebenthal, E.: Pancreatic function and disease in infancy and childhood. Adv. Pediatr., 25: 223 (1978).

20. Milner, J.: Discussion. In: N. P. Mallick: Glucose Polymers In Health and 
Disease: The Role of Caloreen, p. 84 (MTP Press Limited, Lancaster, England, 1977).

21. Morrison, D. F.: Multivariate Statistical Methods, Second Edition, (McGrawHill, New York, 1976).

22. Ohneda, A., Yamagata, S., Tsutsumi, K., and Fujiwara, H.: Distribution of maltose intravenously administered to rabbits and its metabolism in the kidney. Tohoku J. Exp. Med., 112: 141 (1974).

23. Phillips, A. W.: The purification of a yeast maltase. Arch. Biochem. Biophys., 80 346 (1959)

24. Silverman, M.: Brush border disaccharidases in dog kidney and their spatia relationship to glucose transport receptors. J. Clin. Invest., 52: 2486 (1973).

25. Steel, R. G. D. and Torrie, J. H.: Principles and Procedures of Statistics (McGrawHill, New York, 1960)

26. Stegink, L. D., Filer, L. J., Jr., and Baker, G. L.: Effect of aspartame and aspartate loading upon plasma and erythrocyte free amino acid levels in normal adult volunteers. J. Nutr., 107: 1837 (1977).

27. Thorbek, G.: The energetics of protein deposition during growth. Nutr. Metab. 21: 105 (1977)

28. Young, E. A. and Weser, E.: Uptake of maltose and other sugars by rat diaphragm. J. Clin. Invest., 53: 87A (1974). (Abstract).
29. Young, E. A., Drummond, A., Cool, D. A., Cioletti, L. A., Crain, M., Traylor, J. B., and Weser, E.: The effect of insulin on the metabolism of parenteral maltose in man. J. Clin. Endocrinol. Metab., 50: 764 (1980).

30. Young, E. A., Fletcher, J. T., Cioletti, L. A.. Hollrah, L. A., and Weser, E.: Metabolism of continuously infused glucose polymer in man. Am. J. Clin. Nutr., 32: 963 (1979). (Abstract).

31. Young, E. A., Fletcher, J. T.. Cioletti, L. A., Hollrah. L. A., and Weser, E.: The metabolism of parenteral glucose-oligosaccharides in man. J. Parent. Ent. Nutr., 5: 369 (1981).

32. Normosol-R contains $5.26 \mathrm{~g}$ sodium chloride, $2.22 \mathrm{~g}$ sodium acetate, $5.02 \mathrm{~g}$ sodium gluconate, $0.37 \mathrm{~g}$ potassium chloride, and $0.14 \mathrm{~g}$ magnesium chloride per liter of solution. Osmolarity is $295 \mathrm{mOsm}$; the $\mathrm{pH}$ is 6.0 .

33. The present address of Dr. L. B. White is: Pharmaceutical Products Division, Abbott Laboratories, North Chicago, IL 60064.

34. Requests for reprints should be addressed to: Dr. L. D. Stegink, Department of Pediatrics, The University of lowa, Iowa City, IA 52242.

35. This research was supported in part by a grant-in-aid from Abbott Laboratories, North Chicago, IL 60064.

36. Received for publication March 24, 1981.

37. Accepted for publication August 20, 1981

Copyright (C) 1982 International Pediatric Research Foundation. Inc. $0031-3998 / 82 / 1604-0309 \$ 2.00 / 0$

Printed in U.S.A 